Meta

Journal des tradlucteurs

Translators' Journal

\title{
Gestion théâtrale
}

\section{Robert Dubuc}

Volume 22, numéro 2, juin 1977

URI : https://id.erudit.org/iderudit/002611ar

DOI : https://doi.org/10.7202/002611ar

Aller au sommaire du numéro

Éditeur(s)

Les Presses de l'Université de Montréal

ISSN

0026-0452 (imprimé)

1492-1421 (numérique)

Découvrir la revue

Citer cet article

Dubuc, R. (1977). Gestion théâtrale. Meta, 22(2), 125-126.

https://doi.org/10.7202/002611ar

Ce document est protégé par la loi sur le droit d'auteur. L’utilisation des services d'Érudit (y compris la reproduction) est assujettie à sa politique d'utilisation que vous pouvez consulter en ligne.

https://apropos.erudit.org/fr/usagers/politique-dutilisation/
Cet article est diffusé et préservé par Érudit.

Érudit est un consortium interuniversitaire sans but lucratif composé de l’Université de Montréal, l'Université Laval et l'Université du Québec à Montréal. Il a pour mission la promotion et la valorisation de la recherche. https://www.erudit.org/fr/ 


\section{DROBLIEMES ET SOLUTIONS}

\section{GESTION THÉATTRALE}

Ceux qui mettent en doute l'existence du vocabulaire parallèle entre les Etats-Unis et la Grande-Bretagne n'ont qu'à se pencher sur le vocabulaire de la gestion théâtrale pour en recueillir un bon échantillon.

Il y a d'abord la personne que les Américains appellent director et qui fait pendant au producer ${ }^{1}$ des Britanniques. Cette personne a la responsabilité de la réalisation sur scène d'une cuvre dramatique. C'est à elle qu'il incombe de diriger les comédiens, de donner à la pièce le rythme qui lui convient, d'en créer l'atmosphère et d'en déterminer les modalités d'interprétation. Chacun aura reconnu ici le rôle de METTEUR EN SCÈNE.

Aux États-Unis, le mot producer a pris une nouvelle acception : il désigne celui qui porte la responsabilité financière de la production d'une œuvre dramatique. Le mot PRODUCTEUR, déjà utilisé en ce sens au cinéma ${ }^{2}$, pourrait sans inconvénient être appliqué au théâtre.

À côté du metteur en scène, se trouve son bras droit, le stage director. Ici encore on se heurte à des usages divergents de part et d'autre de l'Atlantique. En Angleterre, le stage director ${ }^{3}$ dirige toutes les opérations en coulisse nécessaires au succès de la production. C'est le grand coordonnateur des services de la scène dont il se fait le porte-parole auprès du metteur en scène. Aux États-Unis, c'est le stage manager qui assume ces fonctions, tandis qu'en Angleterre, le stage manager est l'assistant du stage director. Le stage manager anglais correspond à l'assistant stage manager américain, couramment désigné par l'abréviation A.S.M.

La fonction du stage director (G.B.) ou du stage manager (U.S.) correspond en français à DIRECTEUR DE SCÈNE ${ }^{4}$, tandis que celle du stage manager (G.B.) ou de l'assistant stage manager (U.S.) équivaut à celle de RÉGISSEUR ${ }^{5}$. Pour les

1. Peter Cotes, $A$ Handbook for the Amateur Theatre, London, Oldbourne Press, 1957, p. 377.

2. Jean Giraud, Lexique français du cinéma des origines a 1930, Paris, Centre national de la recherche scientifique, 1958 , p. 166.

3. Peter Cotes, op. cit., p. 382.

4. Grand Larousse Encyclopédique, Paris, 1969, vol. 4, p. 111.

5. Id. ibid. 
grandes productions, le régisseur devient RÉGISSEUR GÉNÉRAL et peut être assisté d'un RÉGISSEUR ADJOINT.

Si l'on s'éloigne de la scène pour gravir les paliers administratifs, on arrive chez le DIRECTEUR ARTISTIQUE, personne « qui dirige toute la partie artistique dans un théâtre ou un music-hall ${ }^{6} \gg$. Cette fonction correspond en anglais à celle d'artistic director : « a man who is given the artistic control of a theatre ?."

RoBert DUBuC

\section{RÉSUMÉ TERMINOLOGIQUE}

artistic director

assistant stage manager

(U.S.)

(G.B.)

director (U.S.)

producer (G.B.)

stage director (G.B.)

stage manager (U.S.)

stage manager (G.B.) assistant stage manager

(U.S.)
Personne qui assure la gestion des aspects artistiques d'un théâtre ou d'une troupe.

V. stage manager (G.B.).

Aide du régisseur.

Personne responsable de la réalisation sur scène d'une cuvre dramatique.

V. director (U.S.).

Personne responsable de l'aspect financier de la réalisation sur scène d'une ceuvre dramatique.

Personne qui dirige et coordonne le travail des services scéniques.

Assistant du directeur de scène. directeur artistique

régisseur adjoint

metteur en scène

producteur

directeur de scène

régisseur (général) 